\title{
Comparative Evaluation of Extra Capsular Extraction (ECE) with Suture and Small Incision Cataract Surgery (SICS) Manual without Suture in the University Hospital of Bouake (Ivory Coast)
}

\author{
Diomandé Ibrahim Abib, Bilé Philippe Emile France Koffi, Diomandé Gossé François, \\ Diabaté Zana, Konan Mammi Marie Pascaline, Ouattara Yves, Koffi Kouassi Franck Herman, \\ Kouassi N’Dri Harmand, Koffi Konan Virgile
}

Ophthalmology Department, University Hospital Center of Bouaké, Bouaké, Ivory Coast

Email:philippebile@yahoo.fr

How to cite this paper: Abib, D.I., Koffi, B.P.E.F., François, D.G., Zana, D., Pascaline, K.M.M., Yves, O., Herman, K.K.F., Harmand, K.N. and Virgile, K.K. (2018) Comparative Evaluation of Extra Capsular Extraction (ECE) with Suture and Small Incision Cataract Surgery (SICS) Manual without Suture in the University Hospital of Bouake (Ivory Coast). Open Journal of Ophthalmo$\log , 8,171-179$.

https://doi.org/10.4236/ojoph.2018.83021

Received: July 13, 2018

Accepted: August 26, 2018

Published: August 29, 2018

Copyright $\odot 2018$ by authors and Scientific Research Publishing Inc. This work is licensed under the Creative Commons Attribution International License (CC BY 4.0).

http://creativecommons.org/licenses/by/4.0/

\begin{abstract}
Objective: Cataract is a partial or total opacification of the lens responsible for blindness. The treatment is surgical. The purpose of our study was to evaluate the results of the newly introduced manual small incision cataract surgery (SICS) and compare them with those of the conventional extra-capsular extraction method. Patients and Method: Analytical cross-sectional study was carried out at the ophthalmology department of the University Hospital of Bouaké for a period of 1 year. Results: The two surgical techniques were compared at equal proportions. The average duration of interventions was longer during the sutured Extra Capsular Extraction (ECE) compared to the SICS. Rupture of the posterior capsule with vitreous exit, which was the most observed intraoperative complication, was predominant with ECE with suture (16\%) against $8 \%$ for SICS. Corneal edema observed in the early postoperative period, was predominant with sutured ECE (30\%), against $20 \%$ for SICS. Corneal edema, which was more observed with EEC compared to SICS, dominated secondary and late postoperative complications. Post-operative astigmatism induced by ECE with suture was between -2 and -4 dioptre in 51.5\% of patients and between -0.5 and -2 dioptre in $73.91 \%$ of SICS. Visual acuity without correction in the early days was better with SICS. Conclusion: In this comparative study of cataract surgery, we noted superimposable results for both techniques. However, the prevalence of pre- and post-operative compli-
\end{abstract}


cations was more frequent with sutured ECE. The technique without suture allows visual recovery and a quick return to normal life.

\section{Keywords}

Surgery, Cataract, Performance, Complications, Blindness

\section{Introduction}

Cataract is a partial or total opacification of the lens responsible for a decrease in visual acuity. It is the leading cause of reversible blindness in the world. It is a major public health problem, particularly in developing countries. The only effective treatment to date remains surgery, which has undergone enormous progress in recent decades, moving from intra-capsular extraction to manual extra-capsular extraction with and without suture, and then to phacoemulsification. The development of all these techniques has allowed a faster visual recovery after cataract surgery. In industrialized countries, the rate of cataract surgery is about 5000 per million people each year, but this rate is only $200 /$ million patients in developing countries [1]. The financial reasons and the deficient technical platforms would partly explain this situation, hence the importance of questioning the current surgical offers on the market. The purpose of our study was to evaluate the results of the newly introduced manual small incision cataract surgery (SICS) and compare them to those of the conventional extra-capsular extraction method in the University Hospital of Bouaké. In manual small incision cataract surgery (SICS), the lens is removed through a small scleral incision, followed by placement of an intraocular implant. This incision is self-sealing. In the Extra-capsular Extraction Method (ECE), the lens is removed through a wide corneal incision. An artificial lens is implanted there. The incision is closed by nonabsorbable sutures. Several authors of the literature have compared different aspects of these two surgical techniques [2] [3] [4] [5] [6]. We reviewed these different aspects and we explored other area, in particular, the durations of the interventions and the functional results after optical corrections.

\section{Patients and Methods}

This was a cross-sectional analytical study conducted in the ophthalmology department of the University Hospital of Bouaké (CHU) from January 1, 2014 to December 31, 2014. Included were all patients of any age group who received cataract surgery using either conventional ECE or SICS, regardless of etiology and with a complete medical history. Patients with post traumatic cataract were excluded. The choice of data collection was made on the patients' complete files using a survey sheet designed for this purpose. The information collected in these different files were: socio-demographic characteristics (Age, Sex, profes- 
sion, origin), clinics (reason for consultation, history, ophthalmological examination (visual acuity measurement, slit lamp examination, intraocular pressure measurement, fund us examination)). The surgical protocols compared were the surgical technique of extraction of the crystalline nucleus by the classical method and that by scleral tunnelled micro incision. Postoperative follow-up was done at D1, D7, D14, D30, D45, D60 allowing far vision acuity to be achieved without correction and complications to be assessed. Early postoperative complications were observed before D7. The secondary ones were seen between J7 and J30. The late ones were observed after J30. The VA was classified according to WHO criteria: poor (blindness): corrected VA less than 1/20th; average (visual impairment): corrected VA less than 3/10th and greater than 1/20th; good: corrected VA greater than 3/10th. Measurement of astigmatism and visual acuity with correction was performed at D60 using the RM 9000 canton auto-keratorefractometer. Data analysis was done using epi-info 7, excel. The Pearson Chi2 test or the Fisher test were used to compare proportions. A value of $p<0.05$ was considered significant. The study was carried out with the agreement of the establishment's ethics committee and in confidentiality by assigning an anonymity number to each file.

\section{Results}

A total of one hundred (100) patients were selected and divided equally between the two surgical techniques. The average age of the patients was 63.17 years (Table 1) with the majority male gender (67\%) (Table 2). Housewives (31\%) and peasants (25\%) came first in the professions. The majority of patients (85\%) had consulted for progressive BAV. We also noted that (87\%) of the patients had no specific history. Preoperative visual acuity was less than $1 / 10$ th in $76 \%$ of patients. The normal anterior segment in $96 \%$ of cases. Total white cataract (63\%) was the most observed type of cataract in our patients whose lens was in a generally normal anatomical position (92\%). IOP was normal in most of our patients $(90 \%)$. Senile cataract was more frequent (86\%). Surgically, both surgical

Table 1. Distribution of patients by age $(n=100)$.

\begin{tabular}{ccc}
\hline Age Groups (years) & Number & Percentage \\
\hline$[30-35]$ & 7 & 7 \\
] $35-40]$ & 1 & 1 \\
] $40-45]$ & 4 & 4 \\
] $45-50]$ & 6 & 6 \\
] $50-55]$ & 2 & 2 \\
] $55-60]$ & 10 & 10 \\
] $60-65]$ & 19 & 19 \\
65 & 51 & 51 \\
TOTAL & 100 & 100
\end{tabular}


Table 2. Distribution of patients by sex $(n=100)$.

\begin{tabular}{ccc}
\hline Sex & Number & Percentage \\
\hline Male & 67 & 67 \\
Female & 33 & 33 \\
TOTAL & 100 & 100 \\
\hline
\end{tabular}

techniques were performed in equal proportions. Posterior Chamber Implantation (PCI) was performed in the majority of patients for both techniques. The average duration of interventions was longer for the sutured ECE (17 minutes) compared to the SICS (13 minutes). The most frequent intraoperative complication was the rupture of the posterior capsule with glass exit. It was most often observed during the ECE with suture (16\%). The same was true for corneal edema (30\%) after surgery (Table 3 ). At D60, induced postoperative astigmatism in ECE with suture was between -2 and 4 dioptre in $51.5 \%$ of patients and between -0.5 and -2 dioptre in $73.91 \%$ of patients for SICS (Table 4). Post-operative visual acuity at D1 was classified as average (visual impairment), with both the sutured ECE (62\%) and the SICS (70\%). At D30, she was judged well with the ECE with suture (56\%) and with the SICS (80\%). At D60, it was good (63.7\%) with the ECE with suture and with the SICS (91.3\%) (Table 5). At D60 after correction, Visual Acuity was good (87.9\%) by the ECE with suture and with manual SICS (95.7\%) (Table 6).

\section{Discussion}

Surgery remains the only effective cataract treatment regardless of technique. In our study, the average duration of interventions by ECE with suture was $17 \mathrm{mi}$ nutes with extremes of 13 and 26 minutes. With SICS, the average time was 13 minutes with extremes of 8 and 21 minutes. Based on these results, we can conclude that the technique without suture is faster. There was a statistically significant correlation between the average length of procedures and the surgical technique used $(\mathrm{p}=0.00001)$. Gogate [2] revealed that for eight surgeons practising SICS, their average operation time was 12 minutes (with variations ranging from 6 minutes 19 seconds to 27 minutes 25 seconds). The shorter average intervention time with SICS would be explained in part by the absence of the corneal suture stage with a slightly reduced number of instruments required to perform SICS. However, a good knowledge of the use of both techniques is desirable, as for special circumstances, a surgeon may be forced to convert a SICS to an ECE with suture. This mastery of classic ECE sutures also allows the management of corneal wounds. Per operative complications dominated by ruptures of the posterior capsule with vitreous outlet were observed more frequently during the ECE with suture (16\%) compared to the SICS (8\%). Diallo [3] in Burkina Faso (1.33\%) and Guzek [4] in Ghana (3\%) found ruptures of the posterior capsule with glass exit in the SICS with numbers lower than ours. Daboué [7] (3\%) and Gao [8] (6.7\%) also found figures lower than ours, but slightly higher compared 
Table 3. Distribution of surgical techniques according to postoperative complications.

\begin{tabular}{|c|c|c|c|c|c|c|c|c|c|c|c|c|c|c|}
\hline \multirow{3}{*}{$\begin{array}{c}\text { Complications } \\
\text { Techniques }\end{array}$} & \multicolumn{5}{|c|}{ Early } & \multicolumn{5}{|c|}{ Secondary } & \multicolumn{4}{|c|}{ Late } \\
\hline & \multicolumn{2}{|c|}{ ECE } & \multicolumn{2}{|c|}{ SICS } & \multirow[b]{2}{*}{$\mathrm{P}$} & \multicolumn{2}{|c|}{ ECE } & \multicolumn{2}{|c|}{ SICS } & \multirow[b]{2}{*}{$\mathrm{P}$} & \multicolumn{2}{|c|}{ ECE } & \multicolumn{2}{|c|}{ SICS } \\
\hline & Size & $\%$ & Size & $\%$ & & Size & $\%$ & Size & $\%$ & & Size & $\%$ & Size & $\%$ \\
\hline Corneal oedema & 15 & 30 & 10 & 20 & $\underline{0.248}$ & 10 & 20 & 4 & 8 & $\underline{0.083}$ & 2 & 4 & - & - \\
\hline Marquetry keratitis & 2 & 4 & 7 & 14 & & 2 & 4 & 4 & 5 & & - & - & - & - \\
\hline Wire breakage & 3 & 10 & - & - & & - & - & - & - & & - & - & - & - \\
\hline Hyphema & & & 2 & 4 & - & - & - & 1 & 2 & & - & - & - & - \\
\hline Iris hernia & 1 & 2 & & & & 3 & 6 & - & - & & - & - & - & \\
\hline Hypertonia & 10 & 20 & 8 & 16 & & 3 & 6 & 3 & 6 & & 1 & 2 & & \\
\hline Endophthalmitis & - & - & - & - & & - & - & 1 & 2 & & - & & 1 & 2 \\
\hline
\end{tabular}

ECE: Extra-capsular Extraction. SICS: small incision cataract surgery, P: P value.

Table 4. Distribution of patients according to postoperative astigmatism induced at D60.

\begin{tabular}{cccccc}
\hline Induced astigmatism (D60) in dioptre & ECE & $\%$ & SICS & $\%$ & P \\
\hline$[-05-2]$ & 9 & 27.3 & 17 & 73.91 & $\underline{0.04}$ \\
] $2-4]$ & 17 & 51.5 & 6 & 26.09 & 0.21 \\
] $4-6]$ & 7 & 21.2 & - & - & 0.98 \\
Total & 33 & 100 & 23 & 100 & \\
\hline
\end{tabular}

Table 5. Distribution of post-operative techniques by acuity at a distance without correction.

\begin{tabular}{|c|c|c|c|c|c|c|c|c|c|c|c|c|c|c|c|}
\hline \multirow{3}{*}{$\begin{array}{l}\text { AVL pos-op } \\
\text { Techniques }\end{array}$} & \multicolumn{5}{|c|}{$\mathrm{JI}$} & \multicolumn{5}{|c|}{ J7 } & \multicolumn{5}{|c|}{$\mathrm{J} 30$} \\
\hline & \multicolumn{2}{|c|}{ ECE } & \multicolumn{2}{|c|}{ SICS } & \multirow[b]{2}{*}{$\mathbf{P}$} & \multicolumn{2}{|c|}{$\mathrm{ECE}$} & \multicolumn{2}{|c|}{ SICS } & \multirow[b]{2}{*}{$\mathbf{P}$} & \multicolumn{2}{|c|}{ ECE } & \multicolumn{2}{|c|}{ SICS } & \multirow[b]{2}{*}{$\mathbf{P}$} \\
\hline & Size & $\%$ & Size & $\%$ & & Size & $\%$ & Size & $\%$ & & Size & $\%$ & Size & $\%$ & \\
\hline Poor $\left[1 / 20^{e}<[\right.$ & 15 & 30 & 10 & 20 & 0.25 & 5 & 10 & 4 & 8 & 1.00 & - & - & 1 & 2 & 0.07 \\
\hline $\begin{array}{c}\text { Mean } \\
{\left[1 / 2 s 0^{e}-3 / 10^{e}[\right.}\end{array}$ & 31 & 62 & 35 & 70 & $\underline{0.77}$ & 39 & 78 & 24 & 48 & $\underline{0.001}$ & 22 & 44 & 9 & 18 & $\underline{0.001}$ \\
\hline $\begin{array}{c}\text { Good } \\
{\left[3 / 10^{e}-10 / 10^{e}\right]}\end{array}$ & 4 & 8 & 5 & 10 & 1.00 & 6 & 12 & 22 & 44 & $\underline{0.0002}$ & 28 & 56 & 40 & 80 & 0.01 \\
\hline Total & 50 & 100 & 50 & 100 & & 50 & 100 & 50 & 100 & & 50 & 100 & 50 & 100 & \\
\hline
\end{tabular}

Table 6. Distribution of post-operative techniques according to the acuity at distance before and after correction on D60.

\begin{tabular}{|c|c|c|c|c|c|c|c|c|c|c|}
\hline \multirow{3}{*}{$\begin{array}{c}\text { AVL pos-op D } 60 \\
\text { Techniques }\end{array}$} & \multicolumn{5}{|c|}{ before correction } & \multicolumn{5}{|c|}{ After correction } \\
\hline & \multicolumn{2}{|c|}{ ECE } & \multicolumn{2}{|c|}{ SICS } & \multirow[b]{2}{*}{$\mathbf{P}$} & \multicolumn{2}{|c|}{ ECE } & \multicolumn{2}{|c|}{ SICS } & \multirow[b]{2}{*}{$\mathbf{P}$} \\
\hline & Size & $\%$ & Size & $\%$ & & Size & $\%$ & Size & $\%$ & \\
\hline $\operatorname{Bad}\left[1 / 20^{e}<[\right.$ & 0 & 0 & 0 & 0 & & 0 & 0 & 0 & 0 & \\
\hline $\begin{array}{c}\text { Mean } \\
{\left[1 / 20^{e}-3 / 10^{e}[\right.}\end{array}$ & 10 & 30.3 & 2 & 8.7 & 0.11 & 4 & 12.1 & 1 & 4.3 & 0.60 \\
\hline $\begin{array}{c}\text { Good } \\
{\left[3 / 10^{e}-10 / 10^{e}\right]}\end{array}$ & $23-$ & 63.7 & 21 & 91.3 & $\underline{0.09}$ & 29 & 87.9 & 22 & 95.7 & $\underline{0.63}$ \\
\hline
\end{tabular}


to the SICS by practising the classic extra capsular extraction technique. Tunnelling in SICS ensures a self-sealing opening and maintains a good anterior chamber during the surgical procedure, reducing the risk of capsular or zonular [3] rupture. However, no correlation was established between the surgical technique used and the occurrence of intraoperative complications $(\mathrm{p}=0.372)$. Corneal edema was the most common postoperative complication observed in both techniques. It remains one of the most common complications of cataract surgery. Corneal oedema was predominant in the sutured ECE (30\%) compared to SICS (20\%), comparable to Diallo [3] who found $26.33 \%$ corneal oedema in the SICS technique, while Fanny [9] found 30\% corneal oedema in the sutured ECE technique. Other authors such as Hennig [10] and Gogate [2] find corneal oedema predominant with SICS compared to sutured ECE. The oedema is most often linked to the suffering and/or loss of endothelial cells due to manipulations in the anterior chamber and especially to the manual expulsion of the crystalline nucleus [3]. Natchiar [5] however, estimated that after SICS, endothelial cell loss was minimal (6\%). Hyphema was only observed during the SICS (4\%) and is thought to be related to bleeding generally caused by vascular infractions during tunnel construction. Diallo [3] noted $4.3 \%$ of Hyphema with the SICS in his study. This complication was also observed by John [11] who reported $34 \%$ of cases of hyphema when the tunnels were deep compared to $6 \%$ when they were superficial. These hyphemas had been resolved during post-operative controls. Generally speaking, hyphema caused by the tunnel resolves when it is of small and medium quantity. Washing of the anterior chamber is necessary in case of total hyphema [12] [13]. Cases of suture rupture were observed (6\%) in the ECE technique with suture and required repeat operations in the operating room. The ruptures may be responsible for iris hernia whose management would require a resumption in the operating room for reintegration. Another disadvantage of the ECE technique with suture could be the ocular irritation of the stitches not or badly covered. Postoperative ocular hypertonia was observed in $20 \%$ of patients for ECE with suture versus $16 \%$ in manual SICS with no statistically significant difference $(p=0.602)$. Koffi [14] found $6.32 \%$ hypertonia when Borzeix [15] noted it in $7.4 \%$ of patients. The ocular hypertonia noted in our patients is not specific to an operating technique. It could be secondary to a mechanical phenomenon linked to the abnormal presence (delayed elimination) of the viscoelastic product in the iridocorneal angle. However, authors such as Banchereau [16] do not consider it a complication considering that transient hypertonia would be without consequence. Late postoperative complications were dominated by chronic corneal oedema in 2 patients for ECE with suture. Persistence of corneal oedema beyond the first week may indicate corneal decompensation. At the functional level, $73 \%$ of patients had post-operative astigmatism between -0.5 and $-2 \mathrm{D}$ in manual SICS with mean astigmatism of 1.38 D. In sutured ECE, the majority of patients (51.5\%) had astigmatism between -2.00 and $-4.00 \mathrm{D}$ with mean post-operative astigmatism of 2.31D. A statistical- 
ly significant difference $(\mathrm{p}=0.04)$ was found between astigmatism and the surgical techniques used. SICS without suture would induce less post-operative astigmatism compared to the ECE with suture. These results are identical to those of Diallo [3] in the SICS which found an average post-operative astigmatism of $1.31 \mathrm{D}$ with $73.31 \%$ of patients who had astigmatism below $2 \mathrm{D}$. The same is true for Barequet [17] who found an induced astigmatism of $1.12 \mathrm{D}$ on average. The greater post-operative astigmatism in ECE with suture compared to SICS would be due to the corneal effraction caused by the surgical incision and by the suture performed secondarily. The longer the suture, the more astigmatic it is. Another parameter is the nature of the suture. Indeed, a wire absorbing too quickly will induce a risk of incomplete healing with the risk of reverse astigmatism. Removal of the stitches will reduce the importance of astigmatism, allowing the cornea to gradually regain its anatomical shape. Post-operative visual acuity at D1 judged according to WHO criteria was superimposable for both surgical techniques with no statistically significant difference $(\mathrm{p}=0.77)$. However, according to the WHO, it is recommended less than $5 \%$ of functional results judged poor at D1 postoperatively for cataract surgery. Our scores rated poor for the ECE with suture and with SICS were $30 \%$ and $20 \%$ respectively. They remain well below WHO standards. These results are the consequences of early postoperative complications, in particular oedema, which undergoes rapid resorption in the majority of cases allowing the percentage of poor results to be reduced. At D7, the AVSC was rated good (12\%) for the ECE with suture and with the SICS (44\%). Thus a statistically significant relationship was established between visual acuity at D7 postoperatively between the two techniques $(\mathrm{p}=0.00002)$. In view of these results, functional recovery would be faster with the SICS technique. Same observation made at D30 post-surgery. The results were considered good (56\%) in ECE with suture and with SICS (80\%), always with a statistically significant difference $(\mathrm{P}=0.001)$. Other authors also found better results with CICC compared to ECE, revealing that visual recovery was faster with SICS [18] [19]. At D60, a high number of lost sight was found. However, good visual acuity according to WHO was the majority with SICS (91.3\%), compared to ECE with suture $(63.7 \%)(\mathrm{p}=0.09)$. After correction, the visual acuities judged good were better at $87.9 \%$ in ECE with suture and $95.7 \%$ for SICS ( $p=0.63$ ). At this stage, although functional results are better with SICS, there was no statistically significant difference between the two operating techniques. These results are in line with those of the WHO [20] which stipulate that at four weeks or more after the operation, more than $90 \%$ of cases must have good vision with the best correction. In ECE, the results are slightly below WHO standards. After correction, Guirou [21] also found good visual acuity according to WHO improved but still majority with SICS (75.3\%) compared to ECE with suture (52\%).

At the end of our comparative study of cataract surgery, the results we achieved in most cases were significant. The technique without suture allows visual recovery and a quick return to normal life. However, the long-term out- 
come would be identical to sutured cataract surgery.

\section{Limitations of the Study}

The study has some biases due to the sample that was reduced and the number of patients lost observed at the end of the investigation. There was also a bias in the comparison of intervention times and complications that were likely to occur depending on the different types of cataracts.

\section{References}

[1] Thylefors, B. (2004) Une initiative mondiale pour l'élimination de la cécité évitable. Revue de Sante Oculaire Communautaire, 1, 1-3.

[2] Gogate, P.M. (2005) Comparaison de la chirurgie à petite incision manuelle et de la chirurgie extra capsulaire classique par un essai clinique. Santé Oculaire Communautaire, 2, 8-9.

[3] Diallo, J.W., Meda, N., Ahnoux-Zabsonré, A., Yaméogo, C., Dolo, M., Sanou, J. and Daboué, A. (2015) Résultats fonctionnels de la chirurgie de la cataracte par phacoalternative avec implantation en chambre postérieure: À propos de 300 cas à Bobo Dioulasso (Burkina Faso). Pan African Medical Journal, 20, 230. https://doi.org/10.11604/pamj.2015.20.230.6323

[4] Guzek, J.P. and Ching, A. (2003) Small incision manual extracapsular cataract surgery in Ghana, West Africa. Journal of cataract and refractive surgery, 29, 57-64. https://doi.org/10.1016/S0886-3350(02)01440-2

[5] Natchiar, G. (2000) Evaluation of MSICS (Astigmatism and Endothelial Cell Loss). In: Manual Small Incision Cataract Surgery, Madurai, Aravind Publications, Vol. 4, 43-48.

[6] Riaz, Y., de Silva, S.R. and Evans, J.R. (2013) Manual Small Incision Cataract Surgery (MSICS) with Posterior Chamber Intraocular Lens versus Phacoemulsification with Posterior Chamber Intraocular Lens for Age-Related Cataract. Cochrane Database of Systematic Reviews, 10, CD008813. https://doi.org/10.1002/14651858.CD008813

[7] Daboué, A., Méda, N.D., Ahnoux-Zabsonre, A. and Diallo, J.W. (2002) Complications de l'implantation de cristallin artificiel en chambre postérieure. Médecine d Afrique Noire, 49, 161-165.

[8] Gao, Y., Chen, T. and Zhao, S. (1996) An Analysis of Posterior Capsule Ruptures in Cataract Surgery. Zhonghua Yan KeZaZhi, 32, 200-202.

[9] Fany, A., Keita, C.T., Adjorlolo, A.C., Konan Toure, M.L., Gbe, K., Coulibaly, F., et al. (2001) Accessibilité à l'intervention chirurgicale de la cataracte dans les pays en développement nos résultats des 6 derniers mois chu de Treichville - Abidjan - Côte d'Ivoire. Médecine d' Afrique Noire, 48, 26-29.

[10] Hennig, A., Kumar, J., Yorston, D. and Foster, A. (2003) Sutureless Cataract Surgery with Nucleus Extraction: Outcome of a Prospective Study in Nepal. British Journal of Ophthalmology, 87, 266-270. https://doi.org/10.1136/bjo.87.3.266

[11] John, M.E., Noblitt, R.L., Boleyn, K.L., Raanan, M.G. and Deluca, M.J. (1992) One Million Cataract Surgeries: Swedish National Cataract Register 1992-2009. Journal of Cataract \& Refractive Surgery, 18, 495-499. https://doi.org/10.1016/S0886-3350(13)80105-8

[12] Kutner, B., Fourman, S., Brein, K., Hobson, S., Mrvos, D., Sheppard, J., et al. (1987) 
Aminocaproic Acid Reduces the Risk of Secondary Hemorrhage in Patients with Traumatic Hyphema. Archives of Ophthalmology, 105, 206-208. https://doi.org/10.1001/archopht.1987.01060020060029

[13] Deutsch, T.A., Weinreb, R.N. and Goldberg, M.F. (1984) Indications for Surgical Management of Hyphema in Patients with Sickle Cell Trait. Archives of Ophthalmology, 102, 566-569. https://doi.org/10.1001/archopht.1984.01040030444022

[14] Koffi, K.V., Diomandé, I.A., Diomandé, G.F., Ouattara, Y., Bilé, P.E.F.K., Diabaté, Z., et al. (2015) Chirurgie de la cataracte au centre Hospitalier et Universitaire de Bouaké: Aspects epidemiocliniques et résultats fonctionnels. Revue SOAO, 1, 39-45.

[15] Borzeix, A., Rivaud, L., Lam, M., Ancel, J.M., Ruffin, X., et al. (1993) L'implantation de chambre postérieure en Afrique noire. A propos de 150 cas suivis pendant 18 mois. Journal Français D' Ophtalmologie, 16, 663-664.

[16] Banchereau, A., Desjardins, L., Rouxel, E., et al. (1988) 150 implants de chambre postérieure: Incidents et accidents. Bulletin de la Société Française d'Ophtalmologie. France, 6-7, 869-873.

[17] Baraquet, I.S., Yu, E., Vitale, S., Cassard, S., Azar, D.T. and Stark, W.J. (2004) Astigmatism Outcomes of Horizontal Temporal versus Nasal Clear Incision Cataract Surgery. Journal of Cataract and Refractive Surgery, 30, 418-423. https://doi.org/10.1016/S0886-3350(03)00492-9

[18] Oye, J.E., Kuper, H., Dineen, B., Befidi-Mengue, R. and Foster, A. (2006) Prevalence and Causes of Blindness and Visual Impairment in Muyuka: A Rural Health District in South West Province, Cameroon. British Journal of Ophthalmology, 90, 538-542. https://doi.org/10.1136/bjo.2005.082271

[19] Schemann, J.F., Inocencio, F., de Lourdes Monteiro, M., Andrade, J., Auzemery, A. and Guelfi, Y. (2006) Blindness and Low Vision in Cape Verde Islands: Results of a National Eye Survey. Ophthalmic Epidemiology, 13, 219-226. https://doi.org/10.1080/09286580600681347

[20] Pouliquen, Y. (2009) Complications de la chirurgie de la cataracte. Revue de santé oculaire communautaire, 6, 1-3.

[21] Guirou, N., Napo, A., Dougnon, A., Bakayoko, S., Sidibé, F., Sidibé, M.K., et al. (2013) Résultats fonctionnels de la chirurgie de la cataracte de l'adulte. Journal Français D'Ophtalmologie, 36, 19-22. https://doi.org/10.1016/j.jfo.2012.04.016 